\title{
VISUAL LOSS IN MAJOR BURN INJURY AFTER ENZYMATIC AND SURGICAL DEBRIDEMENT
}

Fernández-Quinto, Aa; García-Sancho Cb; Cerdeira-Pena Pc; Galeiras-Vázquez Ra; López-Suso MEa; García-Barreiro JJa. aBurn Care Unit; bNeurology Department; cOphthalmology Department - A Coruña University Hospital

Review of an extremely rare complication in a major burn injured patient due to a case: ischemic optic neuropathy (ION).

\section{METHODS}

\section{$85 \%$ total body surface burn injury}

High temperature water

\section{+ caustic soda}

\section{ADMISSION}

- Ventilation support, sedoanalgesia and tracheal intubation.

-Hydroelectrolytic reanimation: $\mathbf{2 7}$ L of Lactate Ringer during $\mathbf{1}^{\text {st }} \mathbf{2 4}$ hours.

- Upper limbs escharotomy, enzymatic debridement (Nexobrid ${ }^{\circledR}$ ), surgical debridements with coverage.

-Hemodynamic instability

\section{Prolonged multiorganic failure}

\section{Ophthalmological follow-up with no complications}

\section{Extubated on 85 post-burn day.}

On 92 post-burn day the patient complained of blindness.

Intraocular pressure $17 \mathrm{mmHg}$.

Fundoscopy: disc pallor.

Carotid arteries doppler: No alterations.

CT scan: No alterations.

Magnetic resonance: Nonspecific minimal widen of subarachnoid perioptic spaces.

Dismissed pharmacological, compressive and infectious causes, the patient was diagnosed of

\section{Optic ischaemic neuropathy}

There is not an effective treatment available and the complication is currently irreversible.

\section{CONCLUSION}

Rare cause of visual loss due to a decreased blood flow through the optic nerve.

Major complication in polytraumatisms that need massive fluid resuscitation and other groups of postoperative patients, but barely described in burned patients

- There is not an effective treatment available for this complication therefore prevention is the principal objective. 